PULMONARY HYPERTENSION

\title{
Phosphodiesterase type 5 and high altitude pulmonary hypertension
}

\author{
A A Aldashev, B K Kojonazarov, T A Amatov, T M Sooronbaev, M M Mirrakhimov, N W Morrell, \\ J Wharton, M R Wilkins
}

Thorax 2005;60:683-687. doi: 10.1136/thx.2005.041954

See end of article for authors' affiliations

.

Correspondence to: Professor M R Wilkins, Experimental Medicine and Toxicology, Imperial College London, Hammersmith Hospital, Du Cane Road, London W12 ONN, UK; m.wilkins@ imperial.ac.uk

Received 4 February 2005 Accepted 27 April 2005

\begin{abstract}
Background: This study explored phosphodiesterase type 5 (PDE5) inhibition as a strategy for treating high altitude pulmonary arterial hypertension (HAPH).

Methods: 689 subjects (313 men) of mean (SD) age 44 (0.6) years living above $2500 \mathrm{~m}$ were screened for HAPH by medical examination and electrocardiography, and $188(27 \%)$ met the criteria for right ventricular hypertrophy. 44 underwent cardiac catheterisation and 29 (66\%) had a resting mean pulmonary artery pressure (PAP) above $25 \mathrm{~mm} \mathrm{Hg}$. 22 patients with a raised mean PAP were randomised to receive sildenafil ( 25 or $100 \mathrm{mg}$ ) or matching placebo taken 8 hourly for 12 weeks.

Results: At 3 months, patients on sildenafil $25 \mathrm{mg} 8$ hourly $(n=9)$ had a significantly $(p=0.018)$ lower mean PAP $(-6.9 \mathrm{~mm} \mathrm{Hg})$ at the end of the dosing interval than those on placebo $(n=8)(95 \% \mathrm{Cl}-12.4$ to $-1.3)$. The treatment effect for sildenafil $100 \mathrm{mg} 8$ hourly $(n=5)$ compared with placebo was $-6.4 \mathrm{~mm} \mathrm{Hg}(95 \% \mathrm{Cl}-12.9$ to 0.1$)$. Both doses improved 6 minute walk distance, the lower dose by $45.4 \mathrm{~m}(95 \% \mathrm{Cl} 11.5$ to $79.4 ; \mathrm{p}=0.011)$ and the higher dose by $40.0 \mathrm{~m}(95 \% \mathrm{Cl} 0.2$ to $79.8 ; \mathrm{p}=0.049)$. Sildenafil was well tolerated. Necroscopic lung specimens from three subjects with HAPH showed abundant PDE5 in the muscular coat of remodelled pulmonary arterioles.

Conclusions: PDE5 is an attractive drug target for the treatment of HAPH and a larger study of the long term effects of PDE5 inhibition in HAPH is warranted.
\end{abstract}

$\mathrm{H}$ igh altitude pulmonary hypertension $(\mathrm{HAPH})$ is a public health problem in the mountainous areas of the world, including Kyrgyzstan where it is common among the highland population. ${ }^{1}$ It is estimated that more than 140 million people reside above $2500 \mathrm{~m}^{2}$ and the number of temporary visitors to mountains is close to 40 million. $^{3}$

HAPH is characterised by increased pulmonary vascular resistance secondary to hypoxia induced pulmonary vasoconstriction and vascular remodelling of pulmonary arterioles. $^{145}$ The vascular remodelling involves all cellular elements of the vessel wall with endothelial dysfunction, extension of smooth muscle into previously non-muscularised vessels, and adventitial thickening. ${ }^{45}$ The result is an increased pressure load on the right ventricle, reduced exercise capacity, and premature death from right ventricular failure. ${ }^{6}$ The structural changes in the pulmonary vasculature are due, at least in part, to hypoxia associated smooth muscle cell proliferation and-together with increased pulmonary vascular tone-represent targets for therapeutic intervention. ${ }^{6}$

The biochemical pathways underlying this pathophysiology are poorly understood, but a reduction in nitric oxide (NO) production is thought to have a role. In animal studies the absence of endothelial nitric oxide synthase increases susceptibility to this condition. ${ }^{7}$ Interestingly, indigenous Tibetans who are acclimatised to life at $3600 \mathrm{~m}$ have twofold higher NO concentrations in exhaled breath than lowlanders, ${ }^{8}$ and inhaled NO has been shown to have beneficial effects on pulmonary haemodynamics in HAPH. ${ }^{9}$

NO has vasorelaxant and antiproliferative effects which are mediated by cyclic GMP. ${ }^{10}$ Cyclic GMP is hydrolysed by phosphodiesterases (PDE). PDE5 is the major PDE subtype present in pulmonary vasculature and is more abundant in the lung than in other tissues. ${ }^{11}$ This offers the possibility of relatively selective pulmonary vasodilatation with little systemic hypotension. Agents with PDE5 inhibitory activity reduce pulmonary artery pressure (PAP) in animal models. ${ }^{12-15}$ In an earlier study we showed that the selective PDE5 inhibitor, sildenafil, has a significant inhibitory effect on the acute pressor response to hypoxia in healthy subjects. ${ }^{12}$ The aim of this study was to investigate the role of PDE5 in regulating PAP and pulmonary vascular resistance (PVR) in patients with HAPH by exploring the haemodynamic response to sildenafil and the distribution of PDE5 enzyme in lung specimens.

\section{METHODS \\ Subjects}

All volunteers (aged 16-86 years) were recruited from the Naryn region of Kyrgystan, altitude 2500-4000 m above sea level. All subjects were native to and residents of Naryn, and spend less than 2 weeks per year below $2500 \mathrm{~m}$. All underwent health screening by history, physical examination, spirometry, blood pressure measurement, and electrocardiography (ECG). Subjects who met ECG criteria for right ventricle hypertrophy (RVH) were invited for right heart catheterisation in Bishkek (760 m above sea level). The ECG criteria for RVH were one of the following patterns: right axis deviation, defined as a frontal plane QRS axis of $\geqslant 90$ degrees; $\mathrm{R}$ wave in lead $\mathrm{Vl}$ of $\geqslant 5 \mathrm{~mm}$, an $\mathrm{R} / \mathrm{S}$ ratio $>1$, and $\mathrm{S}>\mathrm{R}$ in $\mathrm{V} 5$ or V6; a leftward shift in the transition zone (the precordial lead with negative deflections of equal amplitude). Right heart catheterisation was performed with a Swan-Ganz thermodilution catheter (Baxter Healthcare, Compton, UK)

Abbreviations: $\mathrm{CO}$, cardiac output; $\mathrm{HAPH}$, high altitude pulmonary hypertension; $6 \mathrm{MW}$, 6 minute walk test; NO, nitric oxide; PAP, pulmonary artery pressure; PDE5, phosphodiesterase type 5; PVR, pulmonary vascular resistance; $\mathrm{RVH}$, right ventricle hypertrophy 
attached to a Vigilance Monitor (Baxter Healthcare, Compton, USA). Patients with a resting mean PAP of more than $25 \mathrm{~mm} \mathrm{Hg}$ and PVR more than 200 dynes.s $/ \mathrm{cm}^{5}$ were offered treatment by randomisation to sildenafil or placebo for 12 weeks. Patients with co-existing medical conditions (including difficulty walking due to infirmity or arthritis) or who felt unable to travel to the National Center for Cardiology in Bishkek were excluded from the randomisation protocol. Lung specimens were obtained for histological examination from patients from the same population who had died from HAPH. ${ }^{1}$

The study was approved by the local ethics committee of the National Center of Cardiology and Internal Medicine in Bishkek and the Hammersmith Hospitals, Chelsea and Westminster \& Queen Charlotte's Hospitals Trusts. Informed consent was obtained from all subjects and families.

\section{Design of study}

Suitable patients were randomised to receive sildenafil, $25 \mathrm{mg}$ or $100 \mathrm{mg}$, or matching placebo every 8 hours for 12 weeks. The study was double blind. The primary end point was the change in mean PAP from baseline (week 0) after 12 weeks of treatment. Other measures of efficacy were the change in PVR (mean PAP ( $\mathrm{mm} \mathrm{Hg}$ ) - pulmonary capillary wedge pressure $(\mathrm{mm} \mathrm{Hg}) /$ cardiac output $(\mathrm{CO}, 1 / \mathrm{min}) \times 80$ dynes.s $\left./ \mathrm{cm}^{5}\right)$, cardiac output $(\mathrm{l} / \mathrm{min})$, and 6 minute walk (6MW) distance from week 0 after 12 weeks of treatment. The physical limitation domain of the Kansas City Cardiomyopathy Questionaire ${ }^{16}$ was used to assess activity.

Both the baseline (week 0) and 12 week measurements were made at $760 \mathrm{~m}$ in the period 7-10 days after arrival at the hospital. Patients returned to their villages between assessments. Compliance with the protocol was assessed by tablet counts. The 6 minute walk and blood tests were made 24 hours before cardiac catheterisation. Baseline cardiopulmonary haemodynamic measurements were made following standard operating procedures after 30 minutes rest. At 12 weeks these measurements were made 8-10 hours after administration of study medication (trough measurements) and repeated 60 minutes after a dose of study medication was given by mouth ( 1 hour post-dose measurements).

\section{Histological study}

Lung tissue sections were examined from three ethnic Kyrgyz highlanders who had died from HAPH and right ventricular hypertrophy and who had histological evidence of pulmonary vascular remodelling, and from two healthy individuals of similar age from the same region who had died in road traffic accidents. ${ }^{1}$ Dewaxed and rehydrated sections were subjected to proteolytic antigen retrieval with $0.1 \%$ trypsin in $0.1 \%$ calcium chloride $(\mathrm{pH} 7.6)$ at $37^{\circ} \mathrm{C}$ for 8 minutes $^{17}$ and immunostained using the avidin-biotin-peroxidase complex (ABC Elite, Vector) method with 3,3'-diaminobenzidine as substrate. Antisera were raised in rabbits against the $\mathrm{N}$ terminal $1-12$ amino acid residues (MERAGPSFGQQR) of human PDE5Al (code LIP-1) and a C-terminal 341 amino acid sequence (code $\alpha \mathrm{PRO}$ ) common to all three PDE5 splice variants. ${ }^{18} 19$ Smooth muscle and endothelial cells were demonstrated with mouse monoclonal antibodies to $\alpha$ smooth muscle actin ( $\alpha$-SMA; clone IA4, Sigma) and CD31, respectively (clone JC/70A, Dako, Ely, UK). The specificity of PDE5 immunostaining was confirmed by the absence of staining after pre-absorption of diluted antiserum (1:1000) with peptide antigen $(0.001-100 \mu \mathrm{g} / \mathrm{ml})$ and after omission of the primary antisera. Sections were counterstained with haematoxylin, dehydrated, cleared in xylene, mounted in Pertex (CellPath, Hemel Hempstead, UK) and examined by light microscopy.

\section{Statistical analysis}

The data are presented as mean (SD). Changes from baseline to week 12 in the primary end point (mean PAP) and the secondary end points (PVR, CO, physical symptom score, and $6 \mathrm{MW}$ ) were compared between the sildenafil and placebo groups using analysis of variance (ANOVA). The differences between all three treatment groups were compared using ANOVA. If a significant difference was observed between the three treatment groups, comparisons of each treatment group with placebo were conducted. In addition, the combined sildenafil dose groups (sildenafil $25 \mathrm{mg} 8$ hourly and $100 \mathrm{mg}$ 8 hourly) were compared with placebo by ANOVA.

\section{RESULTS}

\section{Subject characteristics}

Electrocardiograms were performed on 689 residents at high altitude (313 men, mean (SD) age 41 (0.6) years). One hundred and eighty eight subjects (27\%, 113 men) had one or more ECG criteria of RVH. Pulmonary artery haemodynamics were measured in 44 highlanders with ECG evidence of RVH and 29 ( 25 men) had a mean resting PAP of $>25 \mathrm{~mm} \mathrm{Hg}$. Assuming that the same proportion (66\%) of the 188 with ECG evidence of RVH had a raised PAP, the estimated prevalence of HAPH in this study population (689 individuals) is $18 \%$. Twenty five patients from the catheterised group with a raised PAP $(>25 \mathrm{~mm} \mathrm{Hg})$ volunteered for randomisation to treatment. Three declined further follow up after randomisation (family commitments prevented them from travelling to Bishkek). Twenty two patients completed the study; their ages and lung function data are shown in table 1 and baseline haemodynamic data in table 2. All subjects reported dyspnoea on moderate exertion at entry and most were judged to be in NYHA/WHO functional class II/III (table 1). There were no clinically significant baseline differences between the treatment groups.

\section{Response to treatment Mean PAP}

There was a statistically significant difference between the three groups in changes from baseline to week 12 in mean PAP measured $8-10$ hours post-dose (trough) $(\mathrm{p}=0.039)$. Sildenafil $25 \mathrm{mg} 8$ hourly reduced mean PAP by $-6.9 \mathrm{~mm} \mathrm{Hg}(95 \% \mathrm{CI}-12.4$ to $-1.3 ; \mathrm{p}=0.018)$ compared with placebo. The treatment effect for the higher dose of sildenafil compared with placebo was $-6.4 \mathrm{~mm} \mathrm{Hg} \mathrm{(95 \%} \mathrm{CI}$ -12.9 to 0.1$)$. When patients receiving sildenafil were combined into a single treatment group, mean PAP at trough was significantly reduced by $-6.7 \mathrm{~mm} \mathrm{Hg}(95 \% \mathrm{CI}-11.6$ to $-1.8)$ compared with placebo $(\mathrm{p}=0.010)$.

A statistically significant difference was also observed between the three groups in changes from baseline to week 12 in mean PAP measured 1 hour post-dose $(\mathrm{p}<0.001)$. Sildenafil $25 \mathrm{mg}$ and $100 \mathrm{mg}$ reduced mean PAP by $-11.4 \mathrm{~mm} \mathrm{Hg}(95 \% \mathrm{CI}-16.7$ to -6.1$)$ and $-11.8 \mathrm{~mm} \mathrm{Hg}$ (95\% CI -18.0 to -5.6$)$, respectively, compared with placebo. When patients receiving sildenafil were combined into a single treatment group, mean PAP at 1 hour post-dose was significantly reduced by $-11.6 \mathrm{~mm} \mathrm{Hg}(95 \% \mathrm{CI}-16.3$ to -6.9) compared with placebo $(\mathrm{p}<0.001)$.

\section{PVR}

There was no statistically significant difference between the three groups in changes from baseline to week 12 in PVR measured at trough levels and at 1 hour post-dose. The treatment effects of sildenafil $25 \mathrm{mg}$ and $100 \mathrm{mg} 8$ hourly compared with placebo at trough levels were 16.2 dyne.s $/ \mathrm{cm}^{5}$ (95\% CI -137.3 to 169.7$)$ and -76.9 dyne.s $/ \mathrm{cm}^{5}$ (95\% CI -257.0 to 103.2). The treatment effect for the lower dose of sildenafil compared with placebo at 1 hour post-dose was 
Table 1 Mean (SD) baseline characteristics of subjects randomised to receive sildenafil or placebo treatment

\begin{tabular}{|c|c|c|c|}
\hline & $\begin{array}{l}\text { Sildenafil } 25 \mathrm{mg} \text { tds } \\
(\mathrm{n}=9)\end{array}$ & $\begin{array}{l}\text { Sildenafil } 100 \mathrm{mg} \text { tds } \\
(\mathrm{n}=5)\end{array}$ & $\begin{array}{l}\text { Placebo } \\
(n=8)\end{array}$ \\
\hline \multicolumn{4}{|l|}{ Age (years) } \\
\hline Mean & $61(8)$ & $60(8)$ & $59(8)$ \\
\hline Range & $44-67$ & $54-72$ & $49-65$ \\
\hline Weight (kg) & $75(10.6)$ & $82(19.2)$ & $70(10.6)$ \\
\hline $\mathrm{BMI}\left(\mathrm{kg} / \mathrm{m}^{2}\right)$ & $30(4.8)$ & $29.5(4.1)$ & $26.1(5.2)$ \\
\hline $\mathrm{FEV}_{1}$ (l) & $2.4(0.7)$ & $2.5(1)$ & $1.9(0.7)$ \\
\hline FVC (I) & $2.9(0.9)$ & $3.3(1.1)$ & $2.6(0.8)$ \\
\hline $\mathrm{PO}_{2}(\mathrm{kPa})$ & $8.6(0.6)$ & $9.1(1.2)$ & $8.4(1.8)$ \\
\hline $\mathrm{PCO}_{2}(\mathrm{kPa})$ & $4.9(0.5)$ & $4.8(0.4)$ & $5.5(1.0)$ \\
\hline $\mathrm{Hb}(\mathrm{g} / \mathrm{d} 1)$ & $16.4(2.4)$ & $15.7(1.5)$ & $16.3(1.7)$ \\
\hline Haematocrit (\%) & $51(6.7)$ & $48(5)$ & $52(7.3)$ \\
\hline $\begin{array}{l}\text { NYHA/WHO functional class } \\
(\mathrm{I} / \mathrm{II} / \mathrm{III})\end{array}$ & $2 / 2 / 5$ & $1 / 2 / 2$ & $1 / 2 / 5$ \\
\hline 6 minute walk $(\mathrm{m})$ & $420(85)$ & 449 (84) & $422(69)$ \\
\hline
\end{tabular}

$\mathrm{BMI}$, body mass index; $\mathrm{FEV}_{1}$, forced expiratory volume in 1 second; $\mathrm{FVC}$, forced vital capacity; $\mathrm{PO}_{2}, \mathrm{PCO}_{2}$, oxygen and carbon dioxide tension; $\mathrm{Hb}$, haemoglobin.

-89.1 dyne.s $/ \mathrm{cm}^{5}$ (95\% CI -214.7 to 36.5 ) and for the higher dose -129.9 dyne.s $/ \mathrm{cm}^{5}$ (95\% CI -277.2 to 17.4 ). For the combined sildenafil treatments the effect size was -17.1 dyne.s $/ \mathrm{cm}^{5} \quad(95 \% \quad$ CI -157.4 to 123.2$)$ and -103.7 dyne.s $/ \mathrm{cm}^{5}$ (95\% CI -215.9 to 8.6 ) for trough and 1 hour post-dose measurements, respectively.

\section{Cardiac output}

There was no statistically significant difference between the three groups in changes from baseline to week 12 in cardiac output measured at trough levels $(p=0.051)$, so no further statistical comparisons were carried out. The treatment effects at trough levels were $-1.0 \mathrm{l} / \mathrm{min}$ (95\% CI -2.1 to 0.1 ) and $0.5 \mathrm{l} / \mathrm{min}$ (95\% CI -0.8 to 1.9 ) for the lower and higher doses of sildenafil compared with placebo. When patients receiving sildenafil were combined into a single treatment group, cardiac output at trough levels was reduced by was $-0.4 \mathrm{l} / \mathrm{min}$ (95\% CI -1.6 to 0.7$)$ but was not significantly different from placebo.

No statistically significant difference was observed between the three groups in changes from baseline to week 12 in cardiac output measured at 1 hour post-dose. The respective treatment effects for the lower and higher doses of sildenafil compared with placebo at 1 hour post-dose were $-0.6 \mathrm{l} / \mathrm{min}$ (95\% CI -1.8 to 0.6 ) and $-0.2 \mathrm{l} / \mathrm{min}(95 \% \mathrm{CI}$ -1.2 to 1.6$)$. For the combined sildenafil treatments the effect size was $-0.3 \mathrm{l} / \mathrm{min}(95 \% \mathrm{CI}-1.4$ to 0.8$)$ for 1 hour post-dose.

\section{MW distance}

There was a statistically significant difference between the three groups in changes from baseline to week 12 in $6 \mathrm{MW}$ distance $(p=0.028)$. The increase on sildenafil $25 \mathrm{mg}$ 8 hourly was $45.4 \mathrm{~m}$ (95\% CI 11.5 to $79.4 ; \mathrm{p}=0.011)$ and on sildenafil $100 \mathrm{mg} 8$ hourly it was $40.0 \mathrm{~m}$ (95\% CI 0.2 to 79.8; $\mathrm{p}=0.049$ ) compared with placebo. For the combined sildenafil treatment groups there was a statistically significant treatment effect size $(\mathrm{p}=0.007)$ of $43.5 \mathrm{~m}$ compared with placebo (95\% CI 13.4 to 72.6 ).

\section{Other parameters}

There was a statistically significant difference between the three groups in changes from baseline to week 12 in physical symptom score $(p=0.024)$. The treatment effect for the lower and higher doses of sildenafil compared with placebo were 8.4 (95\% CI -0.2 to 17.0 ) and 14.0 (95\% CI 4.0 to 24.1 ; $\mathrm{p}=0.009$ ), respectively. For the combined sildenafil treatments the statistically significant treatment effect size $(p=0.012)$ was 10.4 compared with placebo (95\% CI 2.5 to 18.3). There was no significant treatment effect on systemic blood pressure. Sildenafil was well tolerated. All subjects reported some improvement in well being and no adverse effects were reported.

\section{Histological study}

Lungs from three Kyrgyz highlanders who had died from HAPH showed typical features of hypoxia induced vascular

\begin{tabular}{|c|c|c|c|c|c|c|c|c|c|}
\hline \multirow[b]{3}{*}{ Measurement } & \multicolumn{3}{|c|}{ Sildenafil $25 \mathrm{mg}(\mathrm{n}=9)$} & \multicolumn{3}{|c|}{ Sildenafil $100 \mathrm{mg}(\mathrm{n}=5)$} & \multicolumn{3}{|c|}{ Placebo $(n=8)$} \\
\hline & \multirow{2}{*}{$\begin{array}{l}\begin{array}{l}\text { Pre- } \\
\text { treatment }\end{array} \\
\text { Baseline }\end{array}$} & \multicolumn{2}{|l|}{ Week 12} & \multirow{2}{*}{$\begin{array}{l}\begin{array}{l}\text { Pre- } \\
\text { treatment }\end{array} \\
\text { Baseline }\end{array}$} & \multicolumn{2}{|l|}{ Week 12} & \multirow{2}{*}{$\begin{array}{l}\begin{array}{l}\text { Pre- } \\
\text { treatment }\end{array} \\
\text { Baseline }\end{array}$} & \multicolumn{2}{|l|}{ Week 12} \\
\hline & & Baseline & $1 \mathrm{~h}$ post-dose & & Baseline & $1 \mathrm{~h}$ post-dose & & Baseline & $1 \mathrm{~h}$ post-dose \\
\hline mPAP (mm Hg) & $36(8)$ & $30(8)$ & $25(7)$ & $32(3)$ & $26(3)$ & $21(2)$ & $34(6)$ & 35 (12) & $35(11)$ \\
\hline Syst PAP (mm Hg) & $53(11)$ & $47(13)$ & $39(10)$ & $46(5)$ & $41(6)$ & $33(4)$ & $51(7)$ & $55(19)$ & $55(18)$ \\
\hline $\mathrm{CO}(\mathrm{l} / \mathrm{min})$ & $5.3(1.1)$ & $5.0(1.4)$ & $5.4(1.7)$ & $5.5(1.2)$ & $6.6(0.6)$ & $6.4(0.8)$ & $4.6(1.2)$ & $5.3(1.7)$ & $5.3(1.6)$ \\
\hline PVR (dyne. $/ \mathrm{cm}^{5}$ ) & 441 (242) & 391 (243) & $284(204)$ & $328(58)$ & $185(49)$ & $130(39)$ & $457(146)$ & $390(205)$ & $388(208)$ \\
\hline WP $(\mathrm{mm} \mathrm{Hg})$ & $9(1)$ & $9(2)$ & $9(2)$ & $9.6(2.1)$ & $11(2.8)$ & $11(2.8)$ & $9(2)$ & $10(3)$ & $10(3)$ \\
\hline HR (beats/min) & $66(8)$ & $63(10)$ & $62(9)$ & $74(12)$ & $70(14)$ & $69(14)$ & $61(5)$ & $63(8)$ & $62(8)$ \\
\hline $\mathrm{SBP}(\mathrm{mm} \mathrm{Hg})$ & $127(22)$ & $125(19)$ & $124(17)$ & $132(20)$ & $127(8)$ & $125(7)$ & $118(8)$ & $123(13)$ & $123(13)$ \\
\hline DBP $(\mathrm{mm} \mathrm{Hg})$ & $77(10)$ & $78(7)$ & $78(7)$ & $80(7)$ & $81(2)$ & $81(2)$ & $75(5)$ & $75(6)$ & $76(6)$ \\
\hline $\mathrm{SaO}_{2}(\%)$ & $94(3)$ & $95(2)$ & $95(2)$ & $94(2)$ & 95 (1) & 95 (1) & $94(5)$ & $94(5)$ & $94(5)$ \\
\hline
\end{tabular}




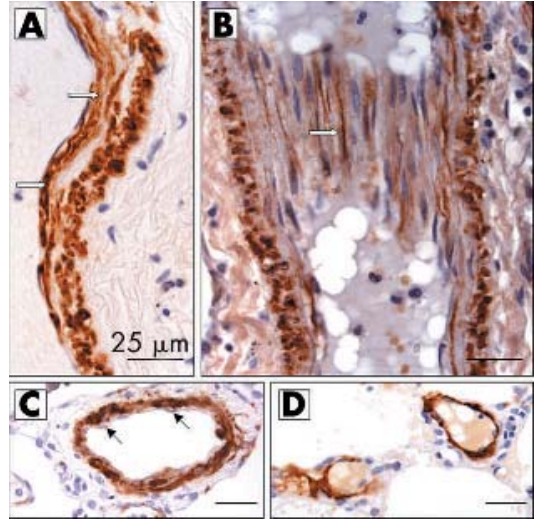

Figure 1 Immunohistochemical localisation of PDE5 in remodelled pulmonary vessels in a lung from a Kyrgyz highlander with high altitude pulmonary hypertension. PDE5 immunostaining is localised to ongitudinal intimal cells ( $A$ and $B$, white arrows) and muscularised distal arterioles in alveolar ducts and alveolar walls (C and D). Endothelial cells lack immunoreactivity (C, black arrows).

remodelling, including the occurrence of longitudinally orientated intimal cells and distal muscularisation of arterioles accompanying alveolar ducts and alveolar walls. ${ }^{15}$ All these cells displayed PDE5 immunostaining (fig 1), as did smooth muscle cells distributed throughout the pulmonary vasculature. PDE5 immunostaining was abolished following pre-absorption of primary antisera with peptide antigen and was not observed in the endothelial or adventitial layers. Lungs from healthy individuals showed a normal distribution of vascular smooth muscle, which also expressed immunoreactive PDE5.

\section{DISCUSSION}

This study shows that the lungs of patients with HAPH have an abundance of PDE5 in the muscularised coat of remodelled pulmonary arteries. Chronic treatment with the PDE5 inhibitor sildenafil was associated with a reduction in mean PAP and an improvement in exercise capacity and physical symptom score. The small number of patients per treatment group resulted in a low power to detect statistically significant differences in other parameters.

Previous studies have provided evidence of therapeutic benefit from sildenafil in patients with pulmonary arterial hypertension, idiopathic or associated with collagen lung disease, ${ }^{20-22}$ and in chronic thromboembolic disease. ${ }^{23}$ Most of these studies have been open label. One study of five patients (four with idiopathic pulmonary arterial hypertension) in which haemodynamic measurements were made by cardiac catheterisation reported a fall in mean PAP and PVR of $18 \mathrm{~mm} \mathrm{Hg}$ and 706 dyne.s $/ \mathrm{cm}^{5}$, respectively, with sildenafil $50 \mathrm{mg}$ three times daily for 3 months. ${ }^{21}$ Another study of nine patients (seven with pulmonary arterial hypertension) reported a $5 \mathrm{~mm} \mathrm{Hg}$ fall in mean PAP with sildenafil $50 \mathrm{mg}$ taken every 8 hours for 3 months. ${ }^{20}$ In 12 patients with chronic thromboembolic disease, sildenafil $50 \mathrm{mg}$ given 8 hourly reduced mean PAP by $7.7 \mathrm{~mm} \mathrm{Hg}$ and PVR by 574 dyne.s $/ \mathrm{cm}^{5}{ }^{23}$ A recent double blind, placebo controlled, crossover study of sildenafil 25-100 mg 8 hourly (dose according to body weight) for 6 weeks in 22 patients with idiopathic pulmonary arterial hypertension reported a $7 \mathrm{~mm} \mathrm{Hg}$ decrease in mean PAP calculated from Doppler echocardiography derived measurements..$^{22}$ In this context, a fall in mean PAP from untreated levels in our study of around $6 \mathrm{~mm} \mathrm{Hg}$ at the end of a dosing interval and $11 \mathrm{~mm} \mathrm{Hg}$ 1 hour after dosing is consistent with these reports.
By comparison, the increase in exercise capacity in our study was modest compared with the effect reported in idiopathic and collagen disease related pulmonary arterial hypertension where $6 \mathrm{MW}$ distance increased by 112-225 m. It is recognised that the natural history of HAPH differs from that of idiopathic pulmonary arterial hypertension and pulmonary hypertension associated with collagen lung disease. It is evident, for example, that life expectancy is substantially better in HAPH. In keeping with this, our study population was older and the baseline 6MW distance was greater $(418-456 \mathrm{~m})$ than in reports of sildenafil use in other forms of pulmonary arterial hypertension studied to date (226-376 m). Nonetheless, physical activity was limited in our patient group, as demonstrated by the questionnaire, and baseline PAP and PVR were raised, even at $760 \mathrm{~m}$. Patients from the same region who died of HAPH had remodelled pulmonary arterioles. The increase in exercise distance and improvement in physical activity score, together with a reduction in PAP, is consistent with a beneficial response to sildenafil.

This study extends our finding in an earlier report that sildenafil attenuates the acute pressor response to hypoxia in healthy Kyrgyz volunteers, ${ }^{12}$ and a recent study in mountaineers and trekkers. ${ }^{24}$ The latter, using echocardiography, reported that sildenafil reduced systolic PAP during exercise and increased maximum exercise performance. The effects of PDE5 inhibition on pulmonary vessels are thought to be mediated by cyclic GMP dependent factors, particularly NO and natriuretic factors. The distribution of PDE5 in remodelled pulmonary arterioles shows that it is well placed to influence the local actions of these factors. Studies in the rat suggest that chronic hypoxia may upregulate PDE5 activity and that this may contribute to the pathophysiology of hypoxia induced pulmonary hypertension. ${ }^{25}$ It was not possible to quantify PDE5 activity in our lung specimens, but increased expression of the enzyme is evident from its aberrant distribution. PDE5 is expressed wherever there is smooth muscle (both vascular and bronchial). Histological examination of HAPH lungs showed typically increased muscularisation including the presence of an extra longitudinally orientated layer in some vessels that is pathognomonic of chronic hypoxia, ${ }^{5}$ and the increased muscularisation demonstrated immunoreactive PDE5. By inhibiting this enzyme, sildenafil would augment the local vasorelaxant and antiproliferative actions of cyclic GMP dependent factors. Given that NO levels are reduced in $\mathrm{HAPH}^{8}$ circulating natriuretic peptide levels-raised as a result of pressure load on the right ventricle-are likely to be the major stimulus of cyclic GMP synthesis in this condition. ${ }^{26}{ }^{27}$ Work in animals exposed to hypoxia $\left(10 \% \mathrm{O}_{2}\right)$ has shown that dosing with sildenafil for 3 weeks reduces pulmonary vascular remodelling as well as PAP. ${ }^{12}{ }^{15}$ Clearly, it is more difficult to establish whether the haemodynamic effects of sildenafil in humans are also accompanied by changes in pulmonary vascular remodelling.

Pulmonary hypertension is a recognised complication of high altitude living - even in ethnic groups that have lived at altitude for many centuries ${ }^{6}$-although accurate prevalence data are difficult to obtain. While not the primary aim of this study, our results suggest that about $18 \%$ of the adult Kyrgyz population resident above $2500 \mathrm{~m}$ have a mean PAP above $25 \mathrm{~mm} \mathrm{Hg}$. This makes the assumption that the group catheterised is representative of the community studied. The ECG lacks sensitivity as a screening tool, but our figure (18\%) compares favourably with an earlier survey in which $20 \%$ of 136 Kyrgyz highlanders had a PAP of more than $25 \mathrm{~mm} \mathrm{Hg}$ on direct measurement. ${ }^{1}$ Others studies based on ECG criteria have reported a prevalence of RVH of $17 \%$ in indigenous Tibetans and $18 \%$ in Peruvian Indians resident at 
$3000-4000 \mathrm{~m} .{ }^{28}$ The view that residence at high altitude over many generations may be protective against the development of HAPH is supported by the observation that ECG evidence of RVH is more common in recently migrated Han Chinese in Tibet (29\%), immigrants from sea level areas to altitude in Peru (28\%), and school age children at $3093 \mathrm{~m}$ in North America (30\%). ${ }^{28}$

It is recognised that the need, for logistical reasons, to conduct cardiac catheterisation in the main academic medical center at $760 \mathrm{~m}$ is a limitation of our study as the patients were removed from their hypoxic environment. It is worth noting, however, that our studies in telemetred rats indicate that, without treatment, PAP does not fall immediately but remains high for several days after removal from chronic exposure to hypoxia ${ }^{15}$ and vascular remodelling persists for a very long time. ${ }^{6}$ Secondly, only one in four subjects with ECG evidence of RVH were willing or able to travel the distance to the hospital for these studies and only 22 patients were able to repeat the hospital visits required for the sildenafil component of the study. As a result, our study lacks power to define the full potential of sildenafil in HAPH and to explore the dose-response relationship.

Nonetheless, sildenafil is a promising treatment for the management of HAPH, a condition for which there are few treatment options. Calcium antagonists are used but have to be given in relatively high doses, lack specificity for the pulmonary vascular bed, and side effects such as ankle oedema are frequent. ${ }^{29}{ }^{30}$ Sildenafil had little effect on systemic blood pressure and was well tolerated. It is relatively expensive for a country with poor health resources, and a larger study of the long term effects of PDE5 inhibition in HAPH is warranted before sildenafil can be widely recommended.

\section{ACKNOWLEDGEMENTS}

The authors are grateful to Pfizer UK for supplies of sildenafil and matching placebo and for the antibody (LIP1) to PDE5.

\section{Authors' affiliations}

A A Aldashev, B K Kojonazarov, Institute of Molecular Biology and Medicine, Bishkek, Kyrgyzstan

T A Amatov, T M Sooronbaev, M M Mirrakhimov, National Center of Cardiology and Internal Medicine, Bishkek, Kyrgyzstan

N W Morrell, Addenbrooke's Hospital, Cambridge, UK

J Wharton, M R Wilkins, Experimental Medicine \& Toxicology, Imperial College London, Hammersmith Hospital, London W12 ONN, UK

This study was supported by British Heart Foundation project grant PG/ 02/024.

Competing interests: MRW has received support from Pfizer for research projects and lectures.

\section{REFERENCES}

1 Aldashev AA, Sarybaev AS, Sydykov AS, et al. Characterization of highaltitude pulmonary hypertension in the Kyrgyz: association with angiotensinconverting enzyme genotype. Am J Respir Crit Care Med 2002; 166:1396-402.

2 Moore LG, Niermeyer S, Zamudio S. Human adaptation to high altitude: regional and life-cycle perspectives. Am J Phys Anthropol 1998;27:25-64.
3 Ward MP, Milledge JS, West J. High altitude medicine and physiology. New York: Oxford University Press, 2000:434.

4 Heath D. Missing link from Tibet. Thorax 1989;44:981-3.

5 Heath D, Williams D, Rios-Dalenz J, et al. Small pulmonary arterial vessels of Aymara Indians from the Bolivian Andes. Histopathology 1990;16:565-71.

6 Maggiorini M, Leon-Velarde F. High-altitude pulmonary hypertension: a pathophysiological entity to different diseases. Eur Respir J 2003;22:1019-25.

7 Fagan KA, McMurtry I, Rodman DM. Nitric oxide synthase in pulmonary hypertension: lessons from knockout mice. Physiol Res 2000;49:539-48.

8 Beall CM, Laskowski D, Strohl KP, et al. Pulmonary nitric oxide in mountain dwellers. Nature 2001;414:411-2.

9 Anand IS, Prasad BA, Chugh SS, et al. Effects of inhaled nitric oxide and oxygen in high-altitude pulmonary edema. Circulation 1998;98:2441-5.

10 Ignarro $L$, Cirino G, Casini A, et al. Nitric oxide as a signaling molecule in the vascular system: an overview. J Cardiovasc Pharmacol 1999;34:879-86.

11 Thomas MK, Francis SH, Corbin JD. Characterisation of a purified bovine lung cGMP-binding cGMP phosphodiesterase. J Biol Chem 1990;265:14964-70

12 Zhao L, Mason NA, Morrell NW, et al. Sildenafil inhibits hypoxia-induced pulmonary hypertension. Circulation $2001 ; 104: 424-8$.

13 Schermuly RT, Kreisselmeier KP, Ghofrani HA, et al. Chronic sildenafil treatment inhibits monocrotaline-induced pulmonary hypertension in rats. Am J Respir Crit Care Med 2004;169:39-45.

14 Itoh T, Nagaya N, Fujii T, et al. A combination of oral sildenafil and beraprost ameliorates pulmonary hypertension in rats. Am J Respir Crit Care Med 2004; 169:34-8.

15 Sebkhi A, Strange JW, Phillips SC, et al. Phosphodiesterase type 5 as a target for the treatment of hypoxia-induced pulmonary hypertension. Circulation 2003; 107:3230-5

16 Green CP, Porter CB, Bresnahan DR, et al. Development and evaluation of the Kansas City Cardiomyopathy Questionnaire: a new health status measure for heart failure. J Am Coll Cardiol 2000;35:1245-55.

17 Cattoretti G, Pileri S, Parravicini C, et al. Antigen unmasking on formalinfixed, paraffin-embedded tissue sections. J Pathol 1993;171:83-98.

18 Stacey P, Rulten S, Dapling A, et al. Molecular cloning and expression of human cGMP-binding cGMP-specific phosphodiesterase (PDE5). Biochem Biophys Res Commun 1999;247:249-54.

19 Lin CS, Lau A, Tu R, et al. Expression of three isoforms of cGMP-binding cGMP-specific phosphodiesterase (PDE5) in human penile cavernosum. Biochem Biophys Res Commun 2000;268:628-35.

20 Mikhail GW, Prasad SK, Li W, et al. Clinical and haemodynamic effects of sildenafil in pulmonary hypertension: acute and mid-term effects. Eur Heart $\mathrm{J}$ 2004;25:431-6.

21 Michelakis ED, Tymchak W, Noga M, et al. Long-term treatment with oral sildenafil is safe and improves functional capacity and hemodynamics in patients with pulmonary arterial hypertension. Circulation 2003;108:2066-9.

22 Sastry BK, Narasimhan C, Reddy NK, et al. A study of clinical efficacy of sildenafil in patients with primary pulmonary hypertension. Indian Heart $J$ 2002;54:410-4.

23 Ghofrani HA, Schermuly RT, Rose F, et al. Sildenafil for long-term treatment of nonoperable chronic thromboembolic pulmonary hypertension. Am J Respir Crit Care Med 2003; 167:1 139-41

24 Ghofrani HA, Reichenberger F, Kohstall MG, et al. Sildenafil increased exercise capacity during hypoxia at low altitudes and at Mount Everest base camp: a randomized, double-blind, placebo-controlled crossover trial. Ann Intern Med 2004;141:169-77.

25 MacLean MR, Johnston ED, McCulloch KM, et al. Phosphodiesterase isoforms in the pulmonary arterial circulation of the rat: changes in pulmonary hypertension. J Pharmacol Exp Ther 1997;283:619-24.

26 Muramatsu M, Tyler RC, Gutkowska J, et al. Atrial natriuretic peptide accounts for increased cGMP in hypoxia-induced hypertensive rat lungs. Am J Physiol 1997;272:L1 126-32.

27 Soodanbekova GK, Batyraliev TA, Niyazova ZA, et al. Atrial natriuretic factor in high-altitude pulmonary hypertension: the influence of acute hypoxia on plasma atrial natriuretic factor, renin, and aldosterone concentrations in highlanders with initially normal or elevated pulmonary artery pressure and without evidence of right ventricular hypertrophy. Angiology 1995;46:833-7.

28 Halperin BD, Sun S, Zhuang J, et al. ECG observations in Tibetan and Han residents of Lhasa. J Electrocardiol 1998;31:237-43.

29 Hackett PH, Roach RC. High-altitude illness. N Engl J Med 2001;345:107-14.

30 Rich S, Kaufmann E, Levy PS. The effect of high doses of calcium-channe blockers on survival in primary pulmomary hypertension. N Engl J Med 1992;327:76-81. 